\title{
How to Analyse Chemical Compounds? A Guide to Compositional Data Analysis Demonstrated with Beer Data
}

\section{Matthias Templ, Barbara Templ}

Submitted date: 27/06/2019 - Posted date: 27/06/2019

Licence: CC BY-NC-ND 4.0

Citation information: Templ, Matthias; Templ, Barbara (2019): How to Analyse Chemical Compounds? A Guide to Compositional Data Analysis Demonstrated with Beer Data. ChemRxiv. Preprint.

In recent years, a lot of analysis was carried out to investigate data on chemical compositions of (non-)alcoholic beverages (whiskey, wine, beer, etc.) and food. However, no study has ever considered the compositional pitfalls inherent in such studies, which may lead to arbitrary results. Two approaches were compared, compositional data analysis ( $\mathrm{CoDa}$ ) and classical statistical analyses. The outcome of compositional data analysis methods provided very well-interpretable results. The method we are proposing is novel in the field of food chemistry, with demonstrated ability to analyse the chemical composition of drinks and food.

File list (1) 
1HOW TO ANALYSE CHEMICAL COMPOUNDS? A GUIDE TO 2COMPOSITIONAL DATA ANALYSIS DEMONSTRATED WITH BEER DATA 3Matthias TEMPL ${ }^{\mathrm{a}, *}$ and Barbara TEMPL ${ }^{\mathrm{b}}$

4

$5^{\text {a }}$ Department of Data Analysis and Process Design, Zurich University of Applied 6Sciences (ZHAW), Switzerland.

$7^{\text {b }}$ Department of Environmental Systems Science, ETH Zurich, Switzerland. E-mail 8address: barbara.a.templ@gmail.com

9*Corresponding author at ZHAW, School of Engineering, Rosenstrasse 3, CH-8400, 10Winterthur, Switzerland. Tel: $+41 \quad(0) 589347807 . \quad$ E-mail address:

11matthias.templ@zhaw.ch

12 


\section{Abstract}

14In recent years, a lot of analysis was carried out to investigate data on chemical 15compositions of (non-)alcoholic beverages (whiskey, wine, beer, etc.). However, no 16study has ever considered the compositional pitfalls inherent in such studies, which 17may lead to arbitrary results. Two approaches were compared, compositional data 18analysis (CoDa) and classical statistical analyses, to demonstrate (i) how aging affects 19beer and (ii) how the results vary depending on the applied approach. Exemplarily, 20chemical compounds (aldehydes, ketones, esters) of 43 beer samples were analyzed. 21Our work has led us to obtain different results, when the analysis (correlation analysis 22and principal component analysis) was conducted on the unmodified-, log23transformed-, or closed-data in contrary to the analyses of log-ratio coordinates. The 24outcome of the latter provided very good separation between aged and fresh beer 25samples and well-interpretable results. The method we are proposing is novel in the 26field of food chemistry, with demonstrated ability to analyze the chemical 27composition of drinks (and food).

28

\section{Keywords}

30chemical composition of drinks, chemometrics, log-ratio analysis, correlation, PCA 31

\section{Introduction}

34 So far, hundreds of articles have been published about the chemical 35 composition of beverages (eg. beer, coffee, wine, whisky, tea). Statistical techniques 36most often applied in such data treatment (Nunes et al., 2015) are cluster analysis, 37principal component analysis (PCA), response surface methodology, k-nearest 38neighbors and artificial neural networks. PCA is for instance widely applied to 39investigate samples of teas (Liu et al., 2014; Wu et al., 2015), tequilas and mezcals 40(another Mexican spirituous beverage; Muoz-Muoz et al., 2010), spirit drinks, wines 41 and various beers (Varmuza et al., 2002; Mannina et al., 2003; Duarte et al., 2004; 42Almeida et al., 2006; Lachenmeier, 2007; Granato et al., 2011; Moura-Nunes et al., 432016; Oladokun, 2016). Correlation analysis is also often used to characterize Indian 44beers (Pai et al., 2015), commercial lager beers (6 dark, 28 pale and 6 alcohol free; 45Blanco et al., 2015), also to show the antioxidant activities (Zhao et al., 2010) and 46phenolics content profile of various beer types (abbey, ale, bock, wheat, lager, pilsner, 
47and dealcoholized; Piazzon et al., 2010). To understand the bitterness of dry-hopped 48beers, Parkin and Shellhammer (2017) used ANOVA and regression analysis, while 49for the characterization of flavour and the chemical composition of lager beers partial 50least squares regression was applied on the raw data by Saison (2010).

51 All these above listed studies have one in common: standard statistical 52methods were applied on compositions without considering the special nature of such 53data. When we look the reviews about the analytical and statistical methods used in 54food science and technology (Granato et al., 2014; Nunes et al., 2015), as well as in 55food chemistry (Kamiloglu, 2019), they do not mention compositional data analysis 56(CoDa; Aitchison, 1986). Food chemistry is a research field where plenty of 57compositional data are available, but where - up to our knowledge and intensive 58research - the scientific community does not use CoDa methods. If traditional 59statistical analysis is applied on compositional data sets, (i) correlations are well 60 known to be arbitrary and even the (ii) arithmetic mean is not an adequate measure as 61the center of the distribution. This may lead to arbitrary results and potential wrong 62conclusions. Therefore, CoDa can be a way to gain additional insights and to see 63beyond a constrained space (simplex).

64 Compositional data are a quantitative description of the parts/compounds of 65some whole, conveying relative information (Aitchison, 1986; tbc in Section 1.4 and 662.2.1), which oft appear in food chemistry. Data can be compositional even if they are 67not closed; and there is no need to close them. It is a myth that compositional data 68sum up to 1 (or 100). Compositional data are typically being represented in 69proportions or percentages, but also in other units, like chemical elements in parts per 70million (ppm), $\mathrm{mg} / \mathrm{kg}$ and $\mathrm{mg} / \mathrm{l}$, which reflect their relative nature. The relative 71information is the most important information about the smell and taste of drinks, the 72absolute numbers and the unit of measurement are less/non-informative. Another 73issue to consider are chemical processes, which may transform certain compounds 74into new compound(s) as described for ground water (Owen et al., 2016). If chemical 75 compounds decrease (or increase) during a chemical process over time (the reaction 76between molecules), the decrease is measured on a relative scale and it is proportional 77 to the whole. Some functional groups dissociate faster than others, but still the 78decrease is on a relative scale and not absolute (otherwise the concentration would get 79negative, which is practically impossible). In case of aging, the relative decrease to 
80the whole or other components is important, as it is demonstrated below with fresh 81and aged beers.

When an analysis is applied on compositional data that follows the 83“Principles of CoDa” (see, e.g., Mateu-Figueras et al., 2011; Boogaart and Tolosana84Delgado, 2013; Filmoser et al., 2018). (1) scale invariance: if a composition is 85multiplied by a constant the results won't change; (2) permutation invariance: 86reordering of variables does not change the results; (3) subcompositional coherence is 87fulfilled if both holds (a) dominance: the distance between two compositions is 88greater equal the distance between a subset of the compositions; (b) ratio preserving: 89the information is included in the ratios and the information of non-selected variables 90does not influence the results if functions applied on subcompostitions. As a result, 91analysis applied on the proportional/constrained data (each element of the vector is 92divided by its row sums) will give the same results as the analysis of the 93unconstrained data. The following simplified examples demonstrate the principles of 94CoDa. Changing the unit of one composition may automatically result in an outlier 95when standard outlier detection methods are applied (violating scale invariance), but 96results are unchanged if CoDa is applied. Consider two margarita cocktail (tequila, 97triple sec, orange juice); one is mixed by a Mexican barkeeper $\mathrm{x}=(0.55,0.40,0.05)$ 98and the other is mixed by a French barkeeper who is fascinated from triple sec, thus $y$ $99=(0.10,0.80,0.10)$, expressed in proportional representation. Their Euclidean 100distance is $d(x, y)=\sqrt{\left\{(0.55-0.10)^{2}+(0.40-0.80)^{2}+(0.05-0.10)^{2}\right\}}=0.604$. When 101only tequila and triple sec are measured, and the compositions expressed as 102proportions, i.e. $0.55 /(0.55+0.40)$, etc., we get $x_{s}=(0.579,0.421)$ and $y_{s}=$ 103(0.111, 0.889), their Euclidean distance is 0.661, which is higher than the distance of 104the whole compositions (violating subcompositional dominance). In addition, if an 105 analysis (e.g. estimation of the correlation) is made on the subcompositions from 106samples containing the proportions of tequila and triple sec only, the results differ if 107the same analysis (e.g. correlation between tequila and triple sec) is made on 108proportions from all three components (violating ratio preserving). It can be also 109easily be seen that such a proportion cannot have larger values than 1 , thus the 110correlation between compositional compounds is forced to be negative or at least to 111be low just as a result of the constrained space. One can show that Euclidean distances 112and standard statistical analysis are not suitable for compositions (see more examples 
113in Filzmoser, Hron, Templ, 2018). However, to best of our knowledge, CoDa has 114some inherent drawback such as 'essential zeros', which does not allow to apply log115ratios in a straightforward manner. It is not easy, how to handle it, but first attempts 116have been made (Templ et al., 2017) - see further discussion on Section 2.2.1.

117 This study was motivated by our practical expertise and theoretical 118background on CoDa that chemists and data analysts in nutrient-, food- and hydro119chemical science may obtain additional insights into their data and receive better 120interpretable results when CoDa methods are applied. Compositional data analysis $121(\mathrm{CoDa})$ with classical statistical analyses were compared to demonstrate (i) the effect 122of aging on the chemical components of beer samples and (ii) how the results vary 123depending on the applied method (correlation analysis, principal component analysis).

\section{4}

\section{MATERIALS AND METHODS}

126To demonstrate the application of CoDa methods in food chemistry, a dataset on 127chemical compounds of beers were used as an example. On a global level, beer 128consumption is much more important than wine or other alcoholic beverages in 129 volume terms (Colen and Swinnen, 2011). Beer brewing is a process, which elaborate 130 four essential raw materials, including barley malt, brewing water, hops and yeast. 131Particularly hops determine the typical beer qualities such as bitter taste, hoppy 132flavour, and foam stability (De Keukeleire, 2000; Schönberger and Kostelecky, 2011). 133Beer experts can recognize a beer brand based on its constant, fresh flavor. However, 134beer-aging results in the production of stale flavors; thus, the original flavor is lost. 135This happens because the beer experiencing flavor deterioration, which is the result of 136both formation and degradation reactions during storage (Vanderhaegen et al., 2006). 137With, e.g., gas chromatography the chemical compounds of beers can be determined. 138It allows identifying the compounds of beer, which are responsible for the stale 139flavors.

\subsection{Beer samples}

142In this study, 43 beer samples were re-analyzed from 14 breweries in Austria, 143Hungary and Romania provided by Varmuza et al. (2002). Their focus was to analyze 144the key volatile chemical compounds of beer samples, in particular the concentration 145levels of aldehydes, ketones and esters (for details see Table 1). 
147Table 1. List of analyzed chemical compounds (chemical name, abbreviation for 148figures, CAS Reg. No., chemical formula and taste characteristics obtained from 149PubChem and references therein, accessed 5.1.2019).

\begin{tabular}{|c|c|c|c|c|c|}
\hline Chemical name & Abbreviation & $\begin{array}{l}\text { PubChe } \\
\text { m CID }\end{array}$ & $\begin{array}{l}\text { CAS } \\
\text { Reg. } \\
\text { No. }\end{array}$ & $\begin{array}{l}\text { Molecular } \\
\text { formula }\end{array}$ & Taste /or comments \\
\hline $\begin{array}{l}\text { 3-methyl- } \\
\text { butyraldehyde }\end{array}$ & 3MeBu-al & 11552 & $\begin{array}{l}590- \\
86-3\end{array}$ & $\mathrm{C}_{5} \mathrm{H}_{10} \mathrm{O}$ & $\begin{array}{l}\text { warm, herbaceous, } \\
\text { slightly fruit and } \\
\text { nut-like taste, apple- } \\
\text { like odor }\end{array}$ \\
\hline $\begin{array}{l}\text { 3-methyl-2- } \\
\text { butanone }\end{array}$ & 3MeBu-on & 11251 & $\begin{array}{l}563- \\
80-4 \\
\end{array}$ & $\mathrm{C}_{5} \mathrm{H}_{10} \mathrm{O}$ & flavoring agent \\
\hline $\begin{array}{l}\text { 2-methyl- } \\
\text { butyraldahyde }\end{array}$ & $2 \mathrm{MeBu}-\mathrm{al}$ & 7284 & $\begin{array}{l}96- \\
17-3\end{array}$ & $\mathrm{C}_{5} \mathrm{H}_{10} \mathrm{O}$ & $\begin{array}{l}\text { almond, cocoa, } \\
\text { fermented, hazelnut, } \\
\text { malt }\end{array}$ \\
\hline capronaldehyde & Hexanal & 6184 & $\begin{array}{l}66- \\
25-1\end{array}$ & $\mathrm{C}_{6} \mathrm{H}_{10} \mathrm{O}$ & $\begin{array}{l}\text { characteristic fruity } \\
\text { taste } \\
\text { and green, woody, } \\
\text { vegetative, apple, } \\
\text { grassy, citrus and } \\
\text { orange with a fresh } \\
\text { lingering aftertaste }\end{array}$ \\
\hline $\begin{array}{l}\text { 2- } \\
\text { (hydroxymethyl)- } \\
\text { furan }\end{array}$ & 2FurMeol & 7361 & $\begin{array}{l}98- \\
00-0\end{array}$ & $\mathrm{C}_{5} \mathrm{H}_{6} \mathrm{O}_{2}$ & $\begin{array}{l}\text { burnt, caramel, } \\
\text { cooked }\end{array}$ \\
\hline heptaldehyde & Heptanal & 8130 & $\begin{array}{l}111- \\
71-7\end{array}$ & $\mathrm{C}_{7} \mathrm{H}_{14} \mathrm{O}$ & citrus, fat, green, nut \\
\hline $\begin{array}{l}2 \text {-furyl methyl } \\
\text { ketone }\end{array}$ & 2AcFur & 14505 & $\begin{array}{l}1192- \\
62-7 \\
\end{array}$ & $\mathrm{C}_{6} \mathrm{H}_{6} \mathrm{O}_{2}$ & flavoring agent \\
\hline 5-methyl furfural & 5Me2Fur & 12097 & $\begin{array}{l}620- \\
02-0\end{array}$ & $\mathrm{C}_{6} \mathrm{H}_{6} \mathrm{O}_{2}$ & flavoring agent \\
\hline furfuryl acetate & EssFuEst & 12170 & $\begin{array}{l}623- \\
17-6\end{array}$ & $\mathrm{C}_{6} \mathrm{H}_{6} \mathrm{O}_{3}$ & fruit \\
\hline $\begin{array}{l}\text { 2-acetyl-5-methyl } \\
\text { furan }\end{array}$ & $2 \mathrm{Ac} 5 \mathrm{MeFu}$ & 14514 & $\begin{array}{l}1193- \\
79-9 \\
\end{array}$ & $\mathrm{C}_{7} \mathrm{H}_{8} \mathrm{O}_{2}$ & nutty-like flavoring \\
\hline $\begin{array}{l}\text { benzene } \\
\text { acetaldehyde }\end{array}$ & 2PhEt-al & 998 & $\begin{array}{l}122- \\
78-1\end{array}$ & $\mathrm{C}_{8} \mathrm{H}_{8} \mathrm{O}$ & $\begin{array}{ll}\text { honey-like, } & \text { sweet, } \\
\text { rose, green, grassy } \\
\text { smell }\end{array}$ \\
\hline $\begin{array}{l}\text { nicotinic } \\
\text { ethylester }\end{array}$ & NicEtEst & 69188 & $\begin{array}{l}614- \\
18-6 \\
\end{array}$ & $\mathrm{C}_{8} \mathrm{H}_{9} \mathrm{NO}_{2}$ & flavoring agent \\
\hline $\begin{array}{l}\text { ethyl } \\
\text { phenylacetate }\end{array}$ & 2PhEssEt & 7590 & $\begin{array}{l}101- \\
97-3 \\
\end{array}$ & $\begin{array}{l}\mathrm{C}_{10} \mathrm{H}_{12} \mathrm{O} \\
2\end{array}$ & $\begin{array}{l}\text { tasting sweet and } \\
\text { fruity }\end{array}$ \\
\hline $\begin{array}{l}\text { gamma-nonanoic } \\
\text { lactone }\end{array}$ & gNonalac & 7710 & $\begin{array}{l}104- \\
61-0\end{array}$ & $\mathrm{C}_{9} \mathrm{H}_{16} \mathrm{O}_{2}$ & $\begin{array}{l}\text { coconut, creamy, } \\
\text { waxy with fatty } \\
\text { milky notes }\end{array}$ \\
\hline furfural & Furfural & 7362 & $\begin{array}{l}98- \\
01-1\end{array}$ & $\mathrm{C}_{5} \mathrm{H}_{4} \mathrm{O}_{2}$ & \begin{tabular}{ll} 
flavor & \multicolumn{2}{c}{ ingredient. } \\
Beer decreases in \\
taste with higher
\end{tabular} \\
\hline
\end{tabular}




\begin{tabular}{|l|l|l|l|l|l|}
\hline & & & & & $\begin{array}{l}\text { concentrations of } \\
\text { furfural. Toxic oil } \\
\text { with a bitter smell }\end{array}$ \\
\hline $\begin{array}{l}\text { 5-hydroxymethyl- } \\
\begin{array}{l}\text { 2- } \\
\text { furancarboxaldeh } \\
\text { yde }\end{array}\end{array}$ & HMF & 237332 & $\begin{array}{l}67- \\
47-0\end{array}$ & $\mathrm{C}_{6} \mathrm{H}_{6} \mathrm{O}_{3}$ & flavoring agent \\
\hline
\end{tabular}

150

151

152 Observations were made on fresh beer samples (they were stored at $10^{\circ} \mathrm{C}$ for 14 153days), as well as on the same beers after artificial aging. The beers were aged by 154 constantly storing them at $45^{\circ} \mathrm{C}$ for 2 weeks. The chemical measurements of 155 compounds were detected before and after the aging by using gas chromatography156mass spectrometry (GC/MS; Sparkman et al., 2011), after steam distillation (Glinser, 1571999). Only one substance, 5-hydroxymethyl-2-furancarboxaldehyd was analyzed by 158HPLC (Leubolt and Klein, 1989). The units of the measurements/concentrations are 159expressed in mu/l. It is obvious that not the absolute values determine the flavor of the 160beer, but the ratios of variables are important.

161

\subsection{Data analysis}

\subsubsection{Log-ratio analysis of compositional data}

164The sample space of the beer compositional data was defined (after Filzmoser et al., 1652018) as follows:

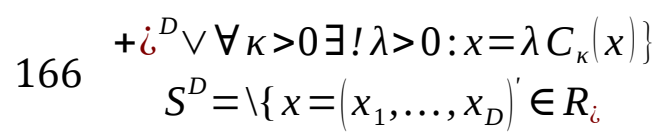

167

168The aim of log-ratio analysis is first to find an orthogonal representation (=log-ratio 169coordinates) of the compositional data in the Euclidean space. The compositions can 170be mapped from $S^{D}$ to the real space $\mathrm{R}^{\mathrm{D}-1}$ by using the family of (isometric) log171ratio transformations. One possible representation of compositional data in $R^{D-1}$ 172are pivot (log-ratio) coordinates (Filzmoser et al., 2018). They are based on the 173isometric log-ratio coordinate representation (Egozcue et.al, 2003) and they form an 174orthogonal basis, given by 
$175 \operatorname{ilr}(x)=z=\left(z_{1}, \ldots, z_{D-1}\right)^{\prime} \quad$ with $\quad z_{j}=\sqrt{\frac{D-j}{D-j+1}} \log \frac{x_{j}}{\sqrt[D-j]{\prod_{k=j+1}^{D} x_{k}}}$ for $176 j=i, \ldots, D-1$.

177

178As it can be seen, the first variable $x_{1}$ only appears in coordinate $z_{1}$, while $179 x_{2}$, for example, appears in both $z_{1}$ and $z_{2} \cdot z_{1}$ can thus be interpreted as 180the relative dominance of $x_{1}$ with respect to the other variables on the average. 181The interpretation of results is mostly done using the coordinate representation. Thus, 182when interpreting the results of a CoDa analysis, the interpretation should rely on the 183log-ratio coordinates and not on the original representation of the data in $S^{D}$.

184 It must be mentioned that CoDa has an inherent drawback, namely the 185problem related to "essential zeros"; the log-ratios are not defined, because of having 186a zero in the numerator or denominator of the ratio. There have been several zero 187replacement strategies suggested by Martín-Fernández et al. (2003), Martín188Fernández and Thio-Henestrosa (2006) and by further authors who have tried to 189contribute to solve this problem (Fry, McLaren, Fry, 2000; Aitchison and Kay, 2003; 190Bacon-Shone, 2003; Wang et al., 2007; Butler and Glasbey, 2008; Scealy and Welsh, 1912011; Martín-Fernández et al., 2015; Templ, Hron, Filzmoser, 2017; Tsagris, Steward, 192Lobachevskii, 2018; Chong and Spencer, 2018). Most of these approaches were 193reviewed by Filzmoser et al. (2018).

194 Depending on the desired application, other representations in (orthonormal) 195log-ratios might be preferable. Often, specific subsets of parts are of interest in 196contrast to another subset of parts, which helps in the interpretation of the results. In 197such cases, other log-ratios are defined via so called balances instead of the pivot 198coordinates (for details, see Filzmoser et al., 2018 or Egozcue and Pawlowski-Glahn, 1992005).

200 In this study, the composition of the beer samples using log-ratio analysis on 201centered log-ratio (orthogonal) coordinates were evaluated. The coordinates were 202obtained by applying a centered log-ratio transformation (Aitchison, 1986), namely by 203dividing each value of a composition of the geometric mean of the composition and 204then taking the logarithm. Besides pairwise log-ratios, centered log-ratio coordinates 205are often used in compositional biplots, because of their simplicity and symmetry 
206(Aitchison and Greenacre, 2001; Filzmoser et al., 2009).

207

\subsubsection{Correlation analysis}

209Measuring the linear dependency between (two) variables is a frequently applied 210method for the analysis of chemical compounds. As already outlined by Pearson 211(1896), computing the correlation between two variables is inappropriate whenever 212the sample space of data is a simplex. It happens because the value automatically be 213forced towards a lower positive or a higher negative one.

214 Variation is one specific CoDa counterpart of a classical correlation (Aitchison 2151986). Here, the variance of log-ratios instead of classical correlation measures were 216calculated. Thus, the variation of Furfural and Hexanal is for instance defined as the 217variance of log (Furfural / Hexanal). If the variation is low, the "correlation" is high. 218If the variation is high, the "correlation" can be said to be low, i.e. the ratios of these 219 two variables differs a lot. Namely, the lower the variation, the stronger the 220correlation. Furthermore, perfect dependency of two parts is given, whenever the 221variation is zero. The Pearson correlations coefficients with their variations were 222 compared to indicate the differences on the results and interpretation.

\section{3}

\subsubsection{Principal component analysis (PCA)}

225PCA allows new projections of the original data to be obtained. Namely, the first 226principal component (the first score vector) is the linear combination of the variables 227of a data set for that it's projected values has the largest variance, thus explaining 228most of the data. PCA is frequently applied to concentrations of drinks and typically 229used for dimension reduction purposes or as an exploratory method to interpret the 230multivariate dependencies in the data set. For the latter one, the resulting first two 231(orthogonal) PCAs are often visualized in a biplot. A biplot allows you to visualize the 232magnitude and sign of each variable's contribution to the first two or three principal 233components, and how each observation is represented in terms of those components.

234 Various biplots were compared resulting from PCAs applied on (1) 235unmodified compositional data, (2) scaled and centered log-transformed 236compositional data, (3) closed data (the values are divided by the row sum), and on 237(4) log-ratio coordinates (the correct approach). The approach (4) means that the 238compositions are represented by (log-ratio) coordinates in the real (Euclidean) space 239by first applying a centered log-ratio transformation (Filzmoser et al., 2009). For (1-3) 
240the correlation matrix (instead of the covariance matrix) was used as input to PCA, 241thus the scaled version of PCA.

242Note, that the effect of CoDa on the outcome is independent from the scale (or change 243of the scale) of the units of the chemical compounds.

244 All analyses were performed using the software and environment $\mathrm{R}$ ( $\mathrm{R}$ 245Development Core Team 2016) and the R package "robCompositions" (Filzmoser et 246al., 2018).

247

\section{Results and Discussion}

\subsection{Comparing results of the correlation analysis}

250The correlation and variation between the chemical compounds of fresh and aged 251beers are shown on Fig 1. The classical correlation analysis of the compounds of 252beers (first column of Fig. 1) does not show much difference between fresh beers 253(first row of Fig. 1), aged beers (second row of Fig. 1), and between all beers analyzed 254together (last row of Fig. 1). The reason is that the correlation is already determined 255by the compositional nature of the data. In this case, large values of an unconstrained 256compositional data set drive the classical correlation positive and make the classical 257correlation results arbitrary (see 2.2.2).

258 A different picture can be drawn for the variation of fresh beers (Fig. 1, top 259right) as it is compared with the correlation matrix of fresh beers (Fig. 1, top left). For 260the aged beers (second row of Fig. 1) such differences are more pronounced. A low 261“correlation” (high variation) can be recognized between two substances 262(2AC5MeFu, EssFuEst) compared to all other compounds, however the variation of 263the other compounds does not differ to a great extent (middle right graphics of Fig. 1). 264 

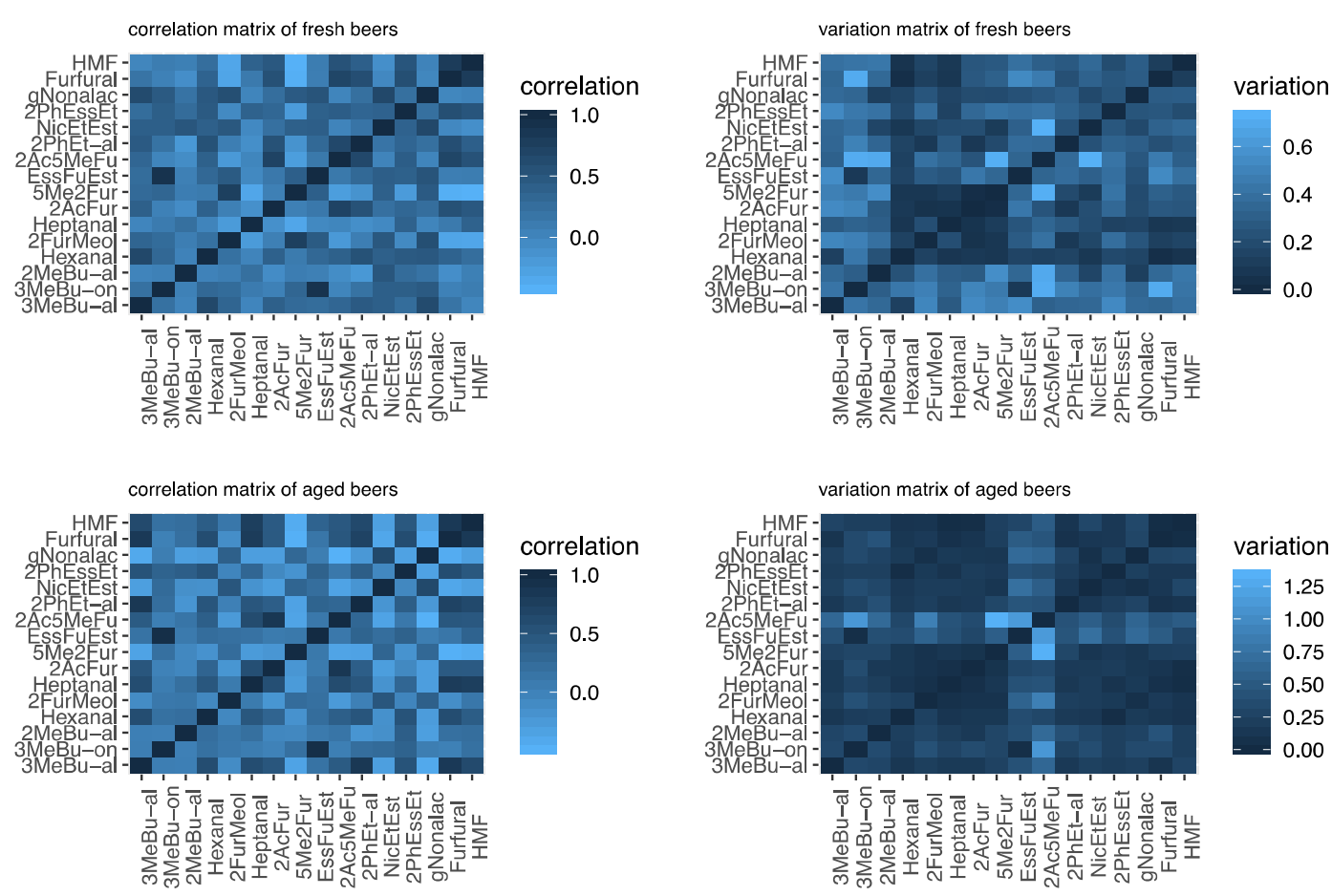

265
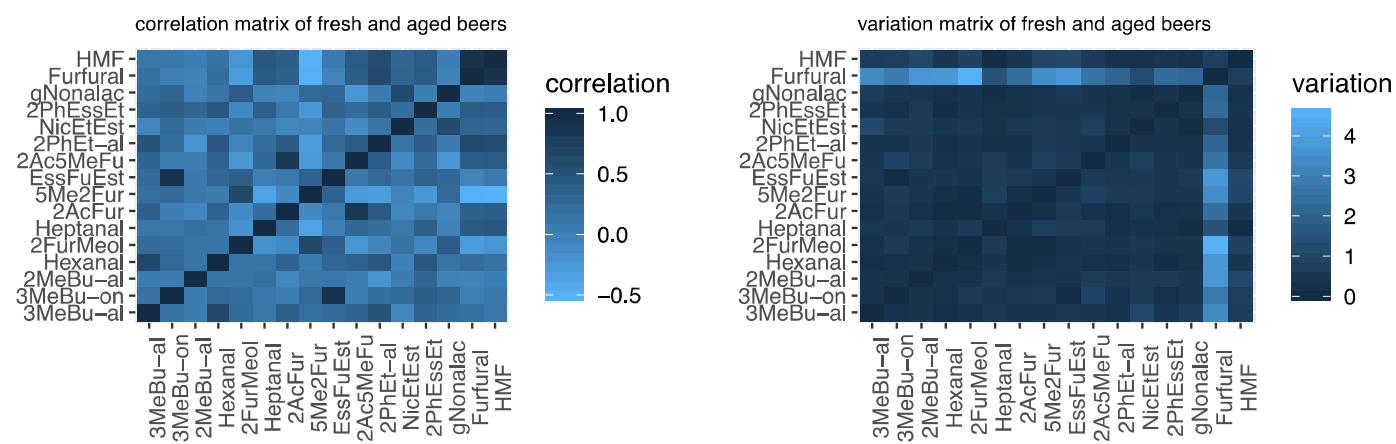

266Fig. 1. Correlation (graphics on the left side) and variation (graphics on the right 267side) between the compounds of beers. The first row shows the results from fresh 268 beers, the second row those from the aged beers, and the last row shows the results 269 for all beers together (fresh and aged).

271The variation matrix of the fresh and aged beers (lower right graphic of Fig. 1.) 272highlights, that the overall variation is driven by Furfural (a toxic oil characterized by 273a bitter smell), which is known to increase in aged beers (Brenner and Khan, 1976). In 274contrary, almost no changes in the compounds of aged beers can be observed based on 275the classical correlation matrices (left graphics of Fig. 1.).

276

2773.2. Comparing results of various PCAs 
278Biplots applied on the raw, log-transformed or closed compositions (thus in its 279original space $S^{D}$, for $S^{D}$ see section 2.2.1), which does not consider the special 280nature of such data are visualized on Fig. 2, 3 and 4. While Figure 5 demonstrates the 281case, when PCA applied on centered log-ratio coordinates.

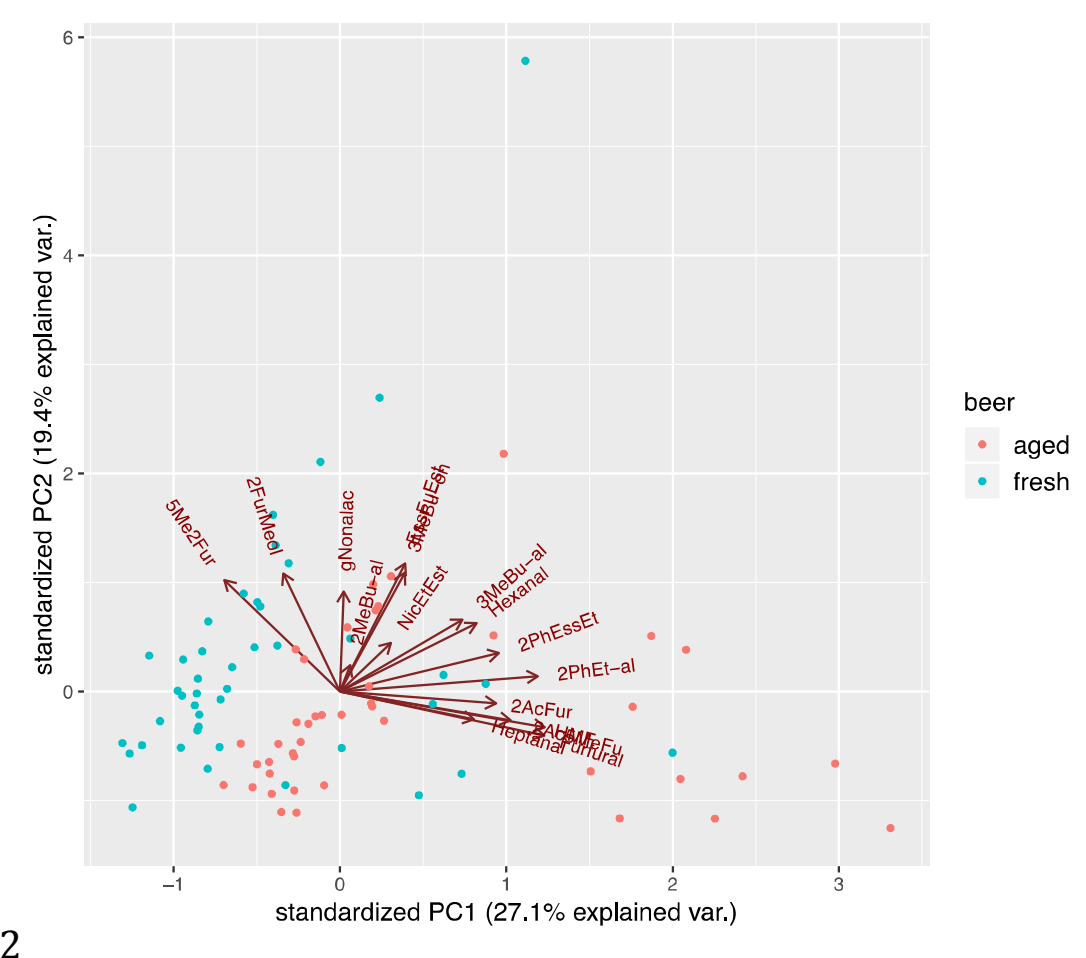

283Fig 2. Biplot resulting from PCA applied on unmodified compositional data. Samples 284are displayed as points, while variables are displayed as vectors on the biplot. The 285arrows represent the chemical compounds (listed in Tab. 1), and the colors 286distinguish aged (old) beer (red points) and fresh beer (blue points).

288It can be observed that almost all arrows of the chemical compounds are pointing 289towards the same direction; therefore, it is difficult to find an acceptable interpretation 290of Fig. 2. It is also detectable that there is no clear separation between fresh and aged 291beers. The explained variance of the first two principal components is also quite low. 292Considering all these aspects, it is not advisable to apply PCA on unmodified 293compositional data.

294In Fig. 3, the biplot of the PCA is shown, when log-transformation was applied on the 295beer compounds. This analysis resulted in a slightly better separated compounds (than 296on Fig. 2), but the compounds are skewed to the upper right area of the graphics and 297an overlap between fresh beers and aged beers is visible, i.e. some aged beers fall into 298the "cluster" of fresh beers. Furthermore, it is noticeable that the explained variance is 
299still rather low (45,2\%). This is basically equivalent to the results of Varmuza et al. $300(2002)$, which provided the motivation for further investigation of the dataset.

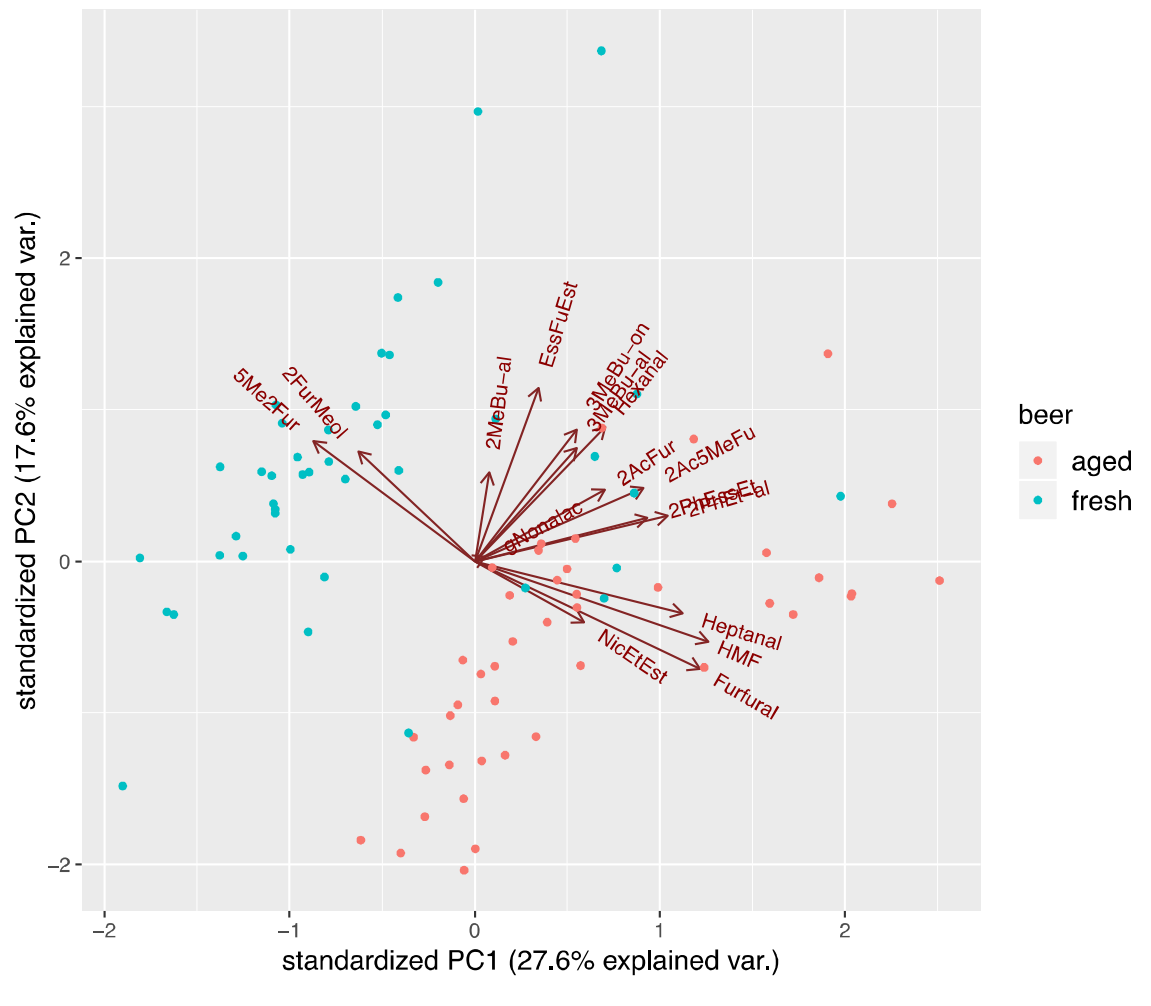

302Fig 3. Biplot resulting from PCA applied on log-transformed compositional data. For 303abbreviations see Fig. 2.

304

305When the compositional values are closed to 1 (or 100), it is difficult to interpret the 306resulting biplot (Fig. 4), especially because the various compounds are located in a 307half-space. It can be concluded that all solution (Fig. 2, 3, 4) are spoiled and arbitrary 308by disrespecting the nature of the compositional data. In addition, the explained 309 variance of the first two principal components is very low. 


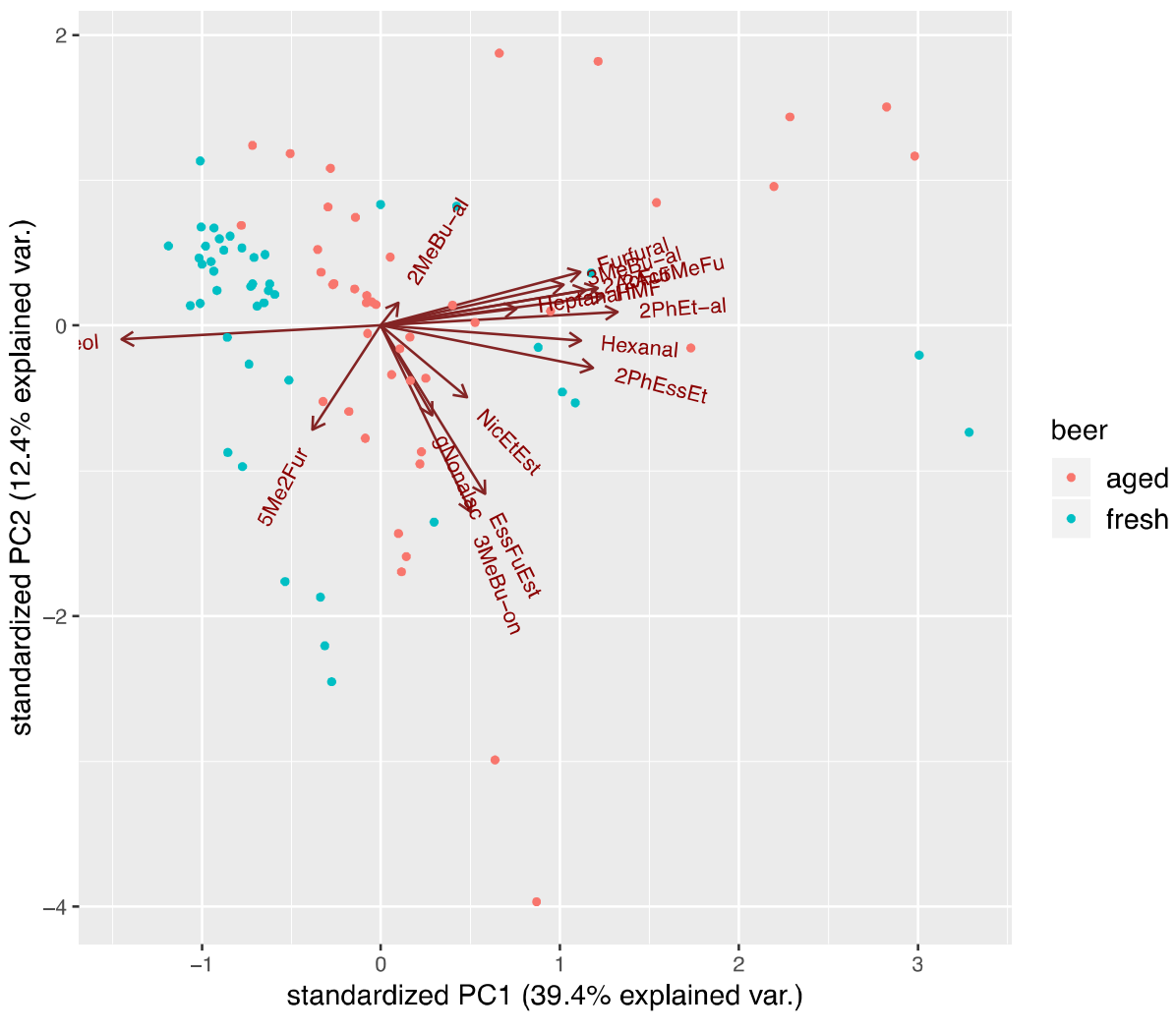

311Fig. 4. Biplot resulting from principal component analysis on closed/proportional 312data. For abbreviations see Fig. 2.

313

314When the PCA is conducted on centered log-ratio coordinates (Fig. 5), the 315compositional biplot is in harmony with the principles of CoDa. 


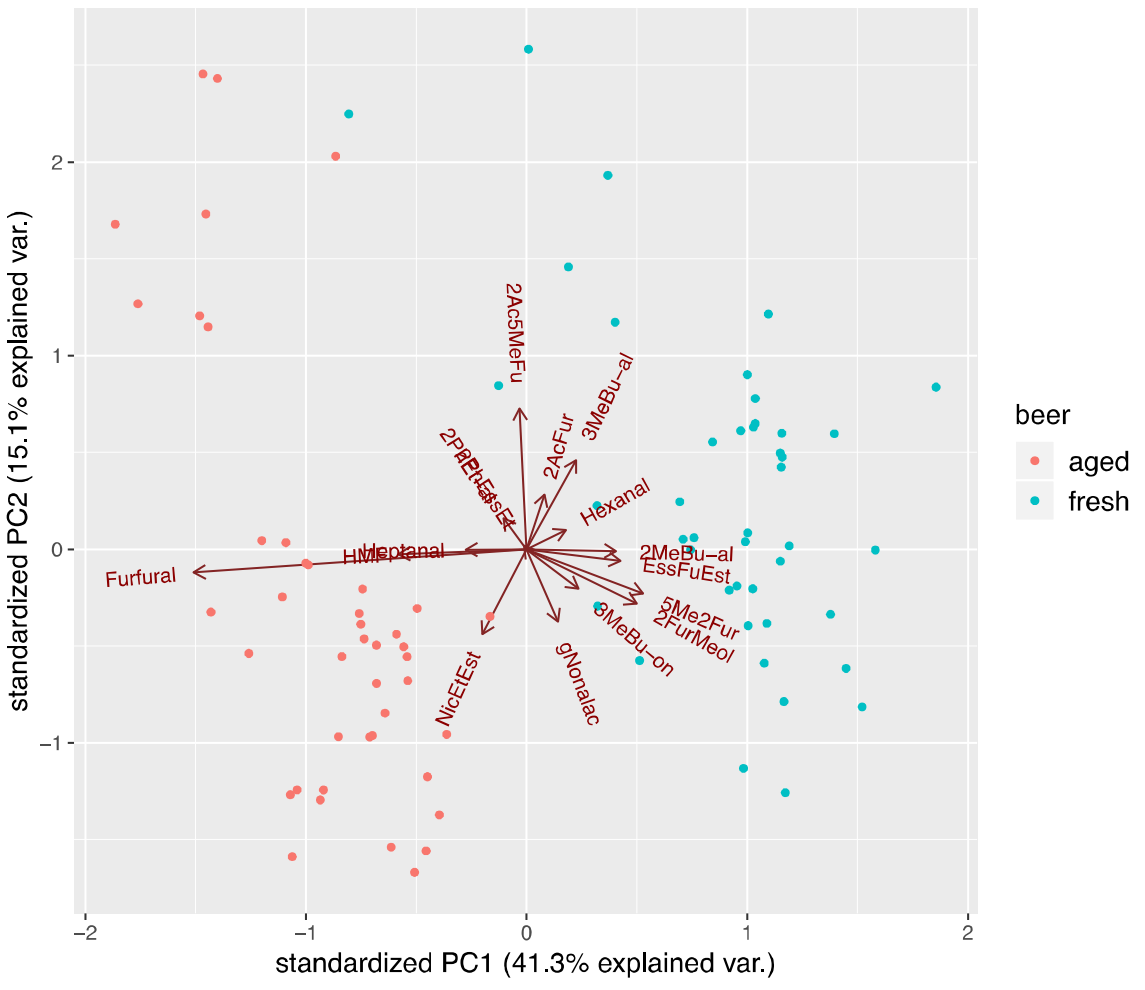

317 Fig. 5. Biplot resulting from PCA on log-ratio coordinates. For abbreviations see Fig. 3182 .

320Since the latter biplot (Fig. 5) is in compliance with the principles of CoDa, the 321arrows (indicating the compounds of the beers) are no longer distorted in a half-space 322and the cosine's of the angle between the arrows approximates the correlation 323between the log-ratio coordinates. Furthermore, a very good separation between aged 324 and fresh beer samples are observable; thus, the interpretation is much easier than in 325any other previously discussed biplots (Fig. 2, 3, and 4).

326 Furfural has the strongest impact on the first principal component (PC; Fig. 3275.), explaining the variance in the dataset. The aged beers pointing towards this 328direction, indicating that the content of Furfural increased (a lot) in the samples of 329aged beers. It can be observed that heptaldehyde (Heptanal) and 5-hydroxymethyl-2330furancarboxaldehyde (HMF) are highly correlated with Furfural and associated with 331the compounds of aged beers. While fresh beers have fruitier, more cocoa, almond 332and caramel taste, since the 2MeBu-al, 2 FurMeol and EssFuEst compounds appear 333on the biplot in positive direction with the first PC. It is to be noted that the group of 334samples in the upper part are samples from a single brewery (not shown in Fig. 5). $335 T h e s e$ samples were determined by $2 \mathrm{Ac} 5 \mathrm{MeFu}$ (organoleptic with nutty-like 
336flavouring), benzene acetaldehyde (2PhEt-al, with honey-like, sweet, rose, green, 337grassy smell), ethyl phenylacetate (2PhEssEt, tasting sweet and fruity), 2-furyl methyl 338ketone (2AcFur, a flavoring agent) and 3-methyl-butyraldehyde (3MeBu-al, slightly 339 fruity and nut-like, herbaceous). Not only Furfural, but other compounds increased 340with aging in samples of this brewery, e.g. 2PhEt-al and 2PhEssEt.

341 The main difference recognizable on Fig. 5., compare to the previous Figures, 342is that the explained variances of the first two principal components increased to 34356.4\%. Note that Varmuza et al. (2002) had difficulties explaining the biplot 344originated from classical PCA applied on log-transformed compositions of the same 345beer dataset. They found (Varmuza et al. 2002) for instance that a special strong fresh 346beer and some Romanian fresh beers had the same flavor (chemical composition) as 347some aged beers. Such questionable pattern cannot be observed using CoDa approach. 348It should be mentioned that other, more sophisticated isometric log-ratio coordinates 349may give further insights about the compounds of beers. For instance, such coordinate 350 could be investigated, which consist the log-ratio of the geometric mean of the 351compounds that indicate fruity tasting against the geometric mean of herbaceous 352 compounds.

\section{3}

\section{Conclusions}

355Compositional data analysis ( $\mathrm{CoDa})$ has been proposed for the investigation of 356chemical composition of beverages demonstrated using beer data. This study has 357highlighted that correlation analysis conducted on raw (unmodified) compositional 358data is problematic, because it becomes spoiled. The research also revealed huge 359differences between the results of the PCAs, when the analysis was conducted on the 360unmodified-, log-transformed-, or closed-data in contrary to the log-ratio coordinates. 361The later one leads to better interpretation, higher explained variance and is 362theoretical sound. The beer data only served as one example data set from food 363chemistry. However, the method we are proposing is novel in the field of food 364chemistry, with demonstrated ability to analyze the chemical composition of drinks 365and food.

367Taken together, these findings suggest to (1) check your data if it is compositional, 368and if it has a compositional nature, (2) use CoDa methods to analyze it. 


\section{Acknowledgement}

371The authors thank Kurt Varmuza (Vienna University of Technology) for providing the 372beer datasets and for his open mind to rethink the approach of analyzing this data set. 373Also, the authors are beyond thankful for Karel Hron (Palacký University Olomouc) 374and Peter Filzmoser's (Vienna University of Technology) joint works on 375compositional data analysis. Furthermore, we would like to thank the CoDa 376community and the whole CoDa association (https://www.coda-association.org/) for 377promoting this important research field of CoDa. This research did not receive any 378specific grant from funding agencies in the public, commercial, or not-for-profit 379 sectors.

380

\section{References}

382Aitchison, J. (1986). The Statistical Analysis of Compositional Data. Journal of the 383Royal Statistical Society. Series B (Methodological), 44, 139-177.

384

385Aitchison, J., \& Greenacre, M. (2002). Biplots of Compositional Data. Journal of the 386Royal Statistical Society. Series C (Applied Statistics), Vol. 51(4), 375-392.

387

388Almeida, C., Duarte, I. F., Barros, A., Rodrigues, J., Spraul, M., \& Gil, A. M. (2006). 389Composition of Beer by ${ }^{1} \mathrm{H}$ NMR Spectroscopy: Effects of Brewing Site and Date of 390Production. Journal of Agricultural and Food Chemistry, 54(3), 700-706.

391

392Blanco, C. A., Nimubona, D., Fernández-Fernández, E., \& Álvarez, I. (2015). Sensory 393Characterization of Commercial Lager Beers and Their Correlations with Iso- $\alpha$-Acid 394Concentrations. Journal of Food and Nutrition Research, 3(1), 1-8.

395

396Boogard, K.G. van der, \& Tolosana-Delgado, R. (2013). Analyzing Compositional 397Data with R. Springer-Verlag Berlin Heidelberg. ISBN 978-3-642-36808-0.

398

399Brenner, M. W., \& Khan, A. A. (1976). Furfural and Beer Color as Indices of Beer 400Flavor Deterioration. Journal of the American Society of Brewing Chemists, 34(1), 40114-19.

402 
403Colen, L., \& Swinnen, J. (2011). Beer drinking nations: The determinants of global 404beer consumption. AAWE Working Paper No.79, Economics, pp 39.

405

406De Keukeleire, D. (2000). Fundamentals of beer and hop chemistry. Quimica Nova, 40723(1), 108-112.

408

409Duarte, I. F., Barros, A., Almeida, C., Spraul, M., \& Gil, A. M. (2004). Multivariate 410analysis of NMR and FTIR data as a potential tool for the quality control of beer. 411Journal of Agricultural and Food Chemistry, 52(5), 1031-1038.

412

413Egozcue, J.J., \& Pawlowsky-Glahn, V. (2005). Groups of parts and their balances in 414compositional data analysis. Mathematical Geology, 37(7), 795-828.

415

416Egozcue, J.J., Pawlowsky-Glahn, V., \& Mateu-Figueras, G. (2003). Isometric logratio 417transformations for compositional data analysis. Mathematical Geology, 35(3), 279418300.

419

420Filzmoser, P., Hron, K., \& Reimann, C. (2009). Principal Component Analysis for 421Compositional Data with Outliers. Environmetrics, 20, 621-632.

422

423Filzmoser, P., Horn, P., \& Templ, M. (2018). Applied Compositional Data Analysis 424with Worked Examples in R. Springer Series in Statistics, ISBN 978-3-319-96422-5. 425

426Glinsner, T. (1999). Rapid methods for the detection of flavor stability in beers (in 427German). Diploma thesis, Vienna University of Technology

428

429Granato, D., Katayama, F. C. U., \& de Castro, I. A. (2011). Phenolic composition of 430South American red wines classified according to their antioxidant activity, retail 431price and sensory quality. Food Chemistry, 129, 366-373.

432

433Granato, D., de Araújo Calado, V. M., \& Jarvis, B. (2014). Observations on the use of 434statistical methods in Food Science and Technology. Food Research International, 55, 435137-149. 
437Kamiloglu, S. (2019). Authenticity and traceability in beverages. Food Chemistry, 438277, 12-24.

439

440Lachenmeier, D. W. (2007). Rapid quality control of spirit drinks and beer using 441multivariate data analysis of Fourier transform infrared spectra. Food Chemistry, 442101(2), 825-832.

443

444Leubolt, R. \& Klein, H. (1989). Ionenaustausch-HPLC im brauereitechnischen 445Analysenlabor. Teil 1, Einführung in die Säulentechnologie, Bestimmung von HMF. 446Monatsschrift für Brauwissenschaft, 42(5), 207-210.

447

448Liu, N., Liang, Y., Bin, J., Zhang, Z., Huang, J., Shu, R. \& Yang. K. (2014). 449Classification of Green and Black Teas by PCA and SVM Analysis of Cyclic 450Voltammetric Signals from Metallic Oxide-Modified Electrode. Food Analytical 451Methods, 7(2), 472-480.

452

453Mateu-Figueras, G., Pawlowsky-Glahn, V., \& Egozcue, J.J. (2011). The principle of 454working on coordinates. In Compositional data analysis: Theory and applications, ed. 455Pawlowsky-Glahn, V. and Buccianti, A., Wiley, pp. 31-42.

456

457Muoz-Muoz, A.C. Pichardo-Molina, J.L., Ramos-Ortz, G., Barbosa-Garca, O., 458Maldonado, J.L., Meneses-Nava, M.A., Ornelas-Soto, N.E., Escobedo, A., \& López459de-Alba, P.L. (2010). Identification and Quantification of Furanic Compounds in 460Tequila and Mezcal using Spectroscopy and Chemometric Methods. Journal of the 461Brazilian Chemical Society, 21(6), 1077-1087.

462

463Moura-Nunes, N., Brito, T. C., da Fonseca, N. D., de Aguiar, P. F., Monteiro, M., 464Perrone, D., \& Torres, A.G (2016). Phenolic compounds of Brazilian beers from 465different types and styles and application of chemometrics for modeling antioxidant 466capacity. Food Chemistry, 199, 105-113.

467

468Nunes, C. A., Alvarenga, V. O., de Souza Sant'Ana, A., Santos, J. S., \& Granato, D. 469(2015). The use of statistical software in food science and technology: Advantages, 470limitations and misuses. Food Research International, 75, 270-280. 
471Oladokun, O., Tarrega, A., James, S., Smart, K., Hort, J., \& Cook, D. (2016). The 472impact of hop bitter acid and polyphenol profiles on the perceived bitterness of beer. 473Food Chemistry, 205, 212-220.

474

4750wen, D. Des. R., Pawlowski-Glahn, V., Egozcue, J. J., Buccianti, A., Bradd, J.M. 476(2016). Compositional data analysis as a robust tool to delineate hydrochemical facies 477within and between gas-bearing aquifers. Water Resources Research, 52(8), 57714785793.

479

480Pai, T. V., Sawant, S. Y., Ghatak, A. A., Chaturvedi, P. A., Gupte, A. M., \& Desai, N. 481S. (2015). Characterization of Indian beers: chemical composition and antioxidant 482potential. Journal of Food Science and Technology, 52(3), 1414-1423.

483

484Parkin, E., \& Shellhammer, T. (2017). Toward Understanding the Bitterness of Dry485Hopped Beer. Journal of the American Society of Brewing Chemists, 75(4), 363-368. 486

487Pearson, K. (1897). Mathematical Contributions to the Theory of Evolution. On a 488Form of Spurious Correlation which may arise when Indices are Used in the 489Measurement of Organs. Proceedings of the Royal Society of London, LX, 489-502. 490

491Piazzon, A., Forte, M., \& Nardini, M. (2010). Characterization of phenolics content 492and antioxidant activity of different beer types. Journal of Agriculture and Food 493Chemistry, 58(19), 10677-10683.

494

495Saison, D., Vanbeneden, N., De Schutter, D. P., Daenen, L., Mertens, T., Delvaux, F., 496\& Delvaux, F. R. (2010). Characterisation of the Flavour and the Chemical 497Composition of Lager Beer after Ageing in Varying Conditions. Brewing Science, 49863(3), 41-53.

499

500Schönberger, C. \& Kostelecky, T. (2011). 125th Anniversary Review: The Role of 501Hops in Brewing. Journal of the Institute of Brewing, 117(3), 259-267.

502

503Sparkman, O. D., Penton, Z. E. \& Kitson, F. G. (2011). Gas Chromatography and 504Mass Spectrometry. A Practical Guide. Elsevier, ISBN 978-0-12-373628-4. 
505Templ, M., Hron, K. \& Filzmoser, P. (2017). Exploratory Tools for Outlier Detection 506in Compositional Data with Structural Zeros. Journal of Applied Statistics, 44 (4), $507734-752$.

508Vanderhaegen, B., Neven, H., Verachtert, H., \& Derdelinckx, G. (2006). The 509chemistry of beer aging - a critical review. Food Chemistry, 95, 357-381.

510

511Varmuza, K., Steiner, I., Glinsner, T., \& Klein, H. (2002). Chemometric Evaluation of 512Concentration Profiles from Compounds relevant in Beer Ageing. European Food 513Research and Technology, 215, 235-239.

514

515Wu, B., He, C., Ma, Y., Shen, J., Zhang, L. H., Peng, Y., \& Xiao, P. (2015) 516Investigation of Free Amino Acid, Total Phenolics, Antioxidant Activity and Purine 517Alkaloids to Assess the Health Properties of Non-Camellia Tea. Acta Pharmaceutica 518Sinica B, 6(2), 170-181.

519

520Zhao, H., Chen, W., Lu, J., Zhao, M. (2010). Phenolic profiles and antioxidant 521activities of commercial beers. Food Chemistry, 119, 1050-1158.

522 
